\title{
Metabolic exercise test data combined with cardiac and kidney indexes, the MECKI score: A multiparametric approach to heart failure prognosis
}

Piergiuseppe Agostoni a,b,c,*, Ugo Corrà d , Gaia Cattadori a , Fabrizio Veglia a , Rocco La Gioia e Angela B. Scardovi ${ }^{\mathrm{f}}$, Michele Emdin ${ }^{\mathrm{g}}$, Marco Metra ${ }^{\mathrm{h}}$, Gianfranco Sinagra ${ }^{\mathrm{i}}$, Giuseppe Limongelli ${ }^{\mathrm{j}}$, Rossella Raimondo ${ }^{\mathrm{k}}$, Federica Re ${ }^{\text {}, ~ M a r c o ~ G u a z z i ~}{ }^{\mathrm{m}}$, Romualdo Belardinelli ${ }^{\mathrm{n}}$, Gianfranco Parati ${ }^{\circ}$, Damiano Magrì $^{\mathrm{p}}$, Cesare Fiorentini ${ }^{\mathrm{a}, \mathrm{b}}$, Alessandro Mezzani ${ }^{\mathrm{d}}$, Elisabetta Salvioni ${ }^{\mathrm{a}}$, Domenico Scrutinio ${ }^{\mathrm{e}}$, Renato Ricci ${ }^{\mathrm{f}}$, Luca Bettari ${ }^{\mathrm{h}}$, Andrea Di Lenarda ${ }^{\mathrm{q}}$, Luigi E. Pastormerlo ${ }^{\mathrm{g}}$, Giuseppe Pacileo ${ }^{\mathrm{j}}$, Raffaella Vaninetti ${ }^{\mathrm{k}}$, Anna Apostolo ${ }^{\mathrm{a}}$, AnnaMaria Iorio ${ }^{\mathrm{a}}$, Stefania Paolillo ${ }^{\mathrm{a}}$, Pietro Palermo ${ }^{\mathrm{a}}$, Mauro Contini ${ }^{\mathrm{a}}$, Marco Confalonieri ${ }^{\mathrm{i}}$, Pantaleo Giannuzzi ${ }^{\mathrm{d}}$, Andrea Passantino ${ }^{\mathrm{e}}$, Livio Dei Cas ${ }^{\mathrm{h}}$, Massimo F. Piepoli ${ }^{\mathrm{r}}$, Claudio Passino ${ }^{\mathrm{g}, \mathrm{s}}$ and on behalf of the MECKI score research group (Appendix 1)

a Centro Cardiologicico Monzino, IRCCS, Milano, Italy

b Dipartimento di Scienze Cardiovascolari, Università di Milano, Milano, Italy

' Department of Respiratory and Critical Care Medicine, University of Washington, Seattle, WA, United States

d Divisione di Cardiologia Riabilitativa, Fondazione Salvatore Maugeri, IRCCS, Istituto Scientifico di Veruno, Veruno, Italy

e Division of Cardiology, "S. Maugeri" Foundation, IRCCS, Institute of Cassano Murge, Bari, Italy

${ }^{f}$ UOC Cardiologia Ospedale S. Spirito - Roma Lungotevere in Sassia 3, Roma, Italy

${ }^{\mathrm{g}}$ Fondazione Gabriele Monasterio, CNR-Regione Toscana, Pisa, Italy

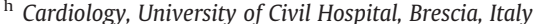

i Cardiovascular Department, Ospedali Riuniti and University of Trieste, Trieste, Italy

j Cardiologia SUN, Ospedale Monaldi (Azienda dei Colli), Seconda Università di Napoli, Napoli, Italy

${ }^{\mathrm{k}}$ Fondazione Salvatore Maugeri, IRCCS, Istituto Scientifico di Tradate, Dipartimento di Medicina e Riabilitazione Cardiorespiratoria Unità Operativa di Cardiologia Riabilitativa,

Tradate, Italy

${ }^{1}$ Cardiology Division, Cardiac Arrhythmia Center and Cardiomyopathies Unit, St.Camillo-Forlanini Hospital, Roma, Italy

m University of Milano, Heart Failure Unit, I.R.C.C.S Policlinico San Donato, San Donato Milanese, Milano, Italy

${ }^{n}$ Cardiologia Riabilitativa, Azienda Ospedali Riuniti, Ancona, Italy

${ }^{\circ}$ Dept of Clinical Medicine and Prevention, University of Milano Bicocca E' Dept of Cardiology, S:Luca Hospital, Istituto Auxologico Italiano, Milano, Italy

p Dipartimento di Medicina Clinica e Molecolare, "Sapienza" Università degli Studi di Roma, Roma, Italy

${ }^{q}$ Centro Cardiovascolare, Azienda per i Servizi Sanitari $n^{\circ} 1$, Trieste, Italy

${ }^{r}$ UOC Cardiologia, G da Saliceto Hospital, Piacenza, Italy

s Scuola Superiore S. Anna, Pisa, Italy

\section{A R T I C L E I N F O}

\section{Article history:}

Received 13 April 2012

Received in revised form 30 May 2012

Accepted 24 June 2012

Available online 15 July 2012

Keywords:

Heart failure

Prognosis

Oxygen consumption

\section{A B S T R A C T}

Objectives: We built and validated a new heart failure (HF) prognostic model which integrates cardiopulmonary exercise test (CPET) parameters with easy-to-obtain clinical, laboratory, and echocardiographic variables.

Background: HF prognostication is a challenging medical judgment, constrained by a magnitude of uncertainty. Methods: Our risk model was derived from a cohort of 2716 systolic HF patients followed in 13 Italian centers. Median follow up was 1041 days (range 4-5185). Cox proportional hazard regression analysis with stepwise selection of variables was used, followed by cross-validation procedure. The study end-point was a composite of cardiovascular death and urgent heart transplant.

Results: Six variables (hemoglobin, $\mathrm{Na}^{+}$, kidney function by means of MDRD, left ventricle ejection fraction

Abbreviations: HF, Heart Failure; SHFM, Seattle Heart Failure Model; CPET, Cardiopulmonary exercise test; HFSS, HF survival score; LVEF, Left Ventricular Ejection Fraction;

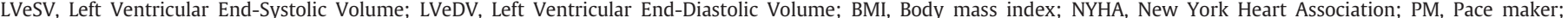

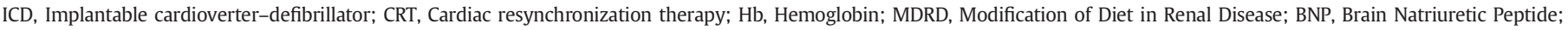

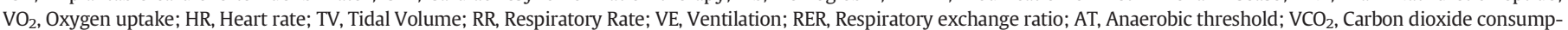
tion; $\mathrm{K}^{+}$, Potassium; $\mathrm{Na}^{+}$, Sodium.

* Corresponding author at: Centro Cardiologico Monzino, IRCCS, Via Parea 4, 20138 Milan, Italy. Tel.: + 390258002586 ; fax: + 390258002283.

E-mail address: piergiuseppe.agostoni@unimi.it (P. Agostoni). 
[echocardiography], peak oxygen consumption [\% pred] and $\mathrm{VE} / \mathrm{VCO}_{2}$ slope) out of the several evaluated resulted independently related to prognosis. A score was built from Metabolic Exercise Cardiac Kidney Indexes, the MECKI score, which identified the risk of study end-point with AUC values of $0.804(0.754-0.852)$ at 1 year, $0.789(0.750-0.828)$ at 2 years, $0.762(0.726-0.799)$ at 3 years and $0.760(0.724-0.796)$ at 4 years.

Conclusions: This is the first large-scale multicenter study where a prognostic score, the MECKI score, has been built for systolic HF patients considering CPET data combined with clinical, laboratory and echocardiographic measurements. In the present population, the MECKI score has been successfully validated, performing very high AUC.

(c) 2012 Elsevier Ireland Ltd. All rights reserved.

\section{Introduction}

The time course of heart failure (HF) is often insidious, and it is influenced by several factors, including functional, neurohumoral and compensatory mechanisms, concomitant diseases as well as psychological well-being, environmental and genetic factors with variable expression and penetrance. Therefore, prognostication is a challenging medical judgment, constrained by a magnitude of uncertainty. Cardiopulmonary exercise test (CPET) is a well recognized, valuable and accurate tool for risk stratification in HF. Among several CPET-derived variables, peak $\mathrm{VO}_{2}[1,2]$, $\mathrm{VE} / \mathrm{VCO}_{2}$ relationship [1,3-5], and their combination [6,7] have been identified as predictors of HF prognosis, and they are used for timing of heart transplant $[2,8,9]$. Although the wealth of information derived from CPET for HF prognosis has been informative and exciting, risk stratification with CPET-derived parameters need to be integrated into clinical practice, and combining them with demographic data, medical history, laboratory values and HF treatment background might be helpful. This aspect has been scantily investigated and analyzed. Indeed, at present, only HF survival score (HFSS) [10] and HF-Action Predictive Risk Score Model [11] include peak $\mathrm{VO}_{2}$ (the former) and exercise duration at CPET (the latter), among other clinical parameters [10,12-14]. However, neither HF-Action Predictive Risk Score Model nor HFSS include ventilatory parameters $[3,4]$ and hemoglobin [15,16], both holding a prognostic value in HF.

Hence, the purpose of the present work was to build a new risk score for systolic HF, integrating measures with potential prognostic value from CPET with established clinical, laboratory and echocardiographic risk factors, in a sizeable multicenter cohort, recruited and followed by experienced HF units in order to identify patients at risk of cardiovascular death and urgent heart transplant. To do so, we used a robust database derived from leading heart failure clinics in Italy.

\section{Methods}

\subsection{Population}

Study cohort consisted of 2716 consecutive systolic HF patients, recruited and prospectively followed in 13 Italian HF centers (see Appendix 2). The first patient was recruited in February 1993 and the last one in September 2009. At enrollment, patients were evaluated, and clinical history, physical, laboratory, ECG, echocardiographic, and CPET data were collected. Inclusion criteria were: previous or present HF symptoms (NYHA functional classes I-III, stage C of ACC/AHA classification) and former documentation of left ventricular systolic dysfunction (left ventricular ejection fraction, $\operatorname{LVEF}<40 \%$ ), stable clinical conditions with unchanged medications for at least three months, ability to perform a CPET, no major cardiovascular treatment or intervention scheduled. Furthermore, only subjects who performed what they considered a maximal effort, regardless of the respiratory quotient reached, were included in the present analysis. Other exclusion criteria were: history of pulmonary embolism, moderate-to-severe aortic and mitral stenosis, pericardial disease, severe obstructive lung disease, exercise-induced angina and significant ECG alterations [17] or presence of any clinical co-morbidity interfering with exercise performance.

\subsection{Clinical, laboratory and echocardiographic evaluations}

We recorded NYHA class, patients' weight and height. HF etiology was defined as: dilative ischemic and non ischemic cardiomyopathy (on the basis of either presence or absence of relevant stenosis at coronary imaging, respectively), or cardiomyopathy secondary to valvular disease, and to other causes. Hemoglobin, serum sodium $\left(\mathrm{Na}^{+}\right)$, potassium $\left(\mathrm{K}^{+}\right)$, and creatinine were measured. We calculated glomerular filtration rate as MDRD by using the following formula: $186.3 *{\text { (crea })^{-1.154} * \text { (Age) }}^{-}$ $0.203 * 0.75$ for women [18]. We recorded left ventricle end-systolic (LVeSV) and end-diastolic volumes (LVeDV) and LVEF (Simpson rule) on echocardiography [19].

\subsection{Cardiopulmonary exercise test}

All CPETs were performed using either an electronically braked cycle-ergometer (2423 patients) or a treadmill (293 patients); for a proper comparison, $\mathrm{VO}_{2}$ data measured on treadmill were reduced by $10 \%$ [20], A ramp protocol and a modified Bruce protocol was applied in CPET with cycle-ergometer and treadmill, respectively. The exercise protocol was set to achieve peak exercise in $\sim 10 \mathrm{~min}$ [21]. In the absence of clinical events, CPET was interrupted when patients stated that they had reached maximal effort. We performed breath-by-breath analysis of expiratory gases and ventilation. Anaerobic threshold was measured by $\mathrm{V}$-slope analysis of $\mathrm{VO}_{2}$ and $\mathrm{VCO}_{2}$, and it was confirmed by ventilatory equivalents and end-tidal pressures of $\mathrm{CO}_{2}$ and $\mathrm{O}_{2}$. If no agreement was obtained, AT was considered as not identified. Exercise-induced periodic breathing was defined as a cyclic fluctuation of ventilation [22]. $\mathrm{VO}_{2}$ /work rate relationship was measured throughout the entire exercise (cycle-ergometer). VE/ $/ \mathrm{VCO}_{2}$ slope was calculated as the slope of the linear relationship between $\mathrm{VE}$ and $\mathrm{VCO}_{2}$ from $1 \mathrm{~min}$ after the beginning of the loaded exercise and the end of the isocapnic buffering period. Peak exercise oxygen pulse was calculated as peak $\mathrm{VO}_{2}$ /peak heart rate (HR). Predicted values of $\mathrm{VO}_{2}$ and $\mathrm{HR}$ were calculated as: peak $\mathrm{VO}_{2}$ pred $=($ Height Age $) * 20$ if male, $=($ Height - Age $) * 14$ if female; peak HR pred $=(220-$ Age $)$, if male, $=(210-$ Age $)$ if female [20].

\subsection{Patients' follow-up and prognosis}

Patient's follow-up was carried out according to the local HF program in a theoretically endless fashion. Follow-up ended with the last clinical evaluation in the center where the patient had been enrolled, or with the patient's death (441 cardiovascular death and 68 non cardiovascular death) or urgent cardiac transplantation $(n=88)$. The study end-point was the composite of cardiovascular death or urgent heart transplant, including in the former stroke. Events were recorded at the follow-up visit. If a patient did not show up at the scheduled follow-up visit, he or his family was contacted by phone call, and the visit was rescheduled according to the patient's desire. If a patient died outside the hospital where he was on follow-up, care was taken to obtain medical records of the event and a report of the cause of death. Patients who died of non-cardiovascular related causes were considered as censored at the time of the event.

\subsection{Data management}

Since several possible sources of error in data recording and transfer might occur throughout a multicenter research study, a data quality control was set up. Centro Cardiologico Monzino (P. A. and G.C.) was the data director center, responsible for data collection, while individual investigators were responsible for their own records Trained investigators were selected within the participating centers. A computerized collection data form was created and approved, and clear rules for fill in were established. Regular feedback to investigators was organized by the data director center: in addition, two "external" experts (M.P. and D.M.), not involved in patients' recruitment, reviewed all the patients' data. Checking data quality included range and consistency checks and checking for missing data. Developing boundaries for out-of-range values required a collaborative effort between the data manager and the investigators, and highest-priority missing data were discussed. Medical personnel who collected the patients' data and defined the cause of death were blinded to the variables used in the MECKI score. All computerized data were stored on a secure network that limited access to authorized individuals.

\section{Statistical analysis}

Categorical variables were presented, such as frequency and percentage, and they were compared by chi-square test. Numerical variables were summarized as means $\pm \mathrm{SD}$, or medians and interquartile 
range when their distribution was markedly non normal, specifically LVeDV and LVeDS. Unpaired t-test or non parametric Mann-Whitney test were used when appropriate for between-group comparison. A $\mathrm{p}<0.05$ was used to define statistical significance.

Predictors for the study end-point were identified by fitting a Cox proportional hazard regression model with stepwise selection of variables measured at starting date. In order to account for the potential heterogeneity among clinical sites, the analysis was stratified by recruiting center. Data from centers with $<200(n=6)$ recruited patients were grouped. The initial set of predictors undergoing selection is reported in Table 1. In order to avoid a spurious selection of predictors, due to the fact that the model was built and tested on the same sample, albeit obtained from several centers, a cross-validation procedure was employed: for 200 times, the sample was randomly split in half, and the model including the independent predictors was selected in the first half (training set) and subsequently tested on the second half (testing set). For each variable, we computed the number of times it was selected in the first step, and the number of times it was confirmed (deemed as significant) in the second step. Among the considered covariates (Table 1), those that were selected and confirmed at least $70 \%$ of the times were considered as independent outcome predictors. A risk score for two-year mortality (or urgent transplant) was then devised as follows: all patients with a censoring time shorter than 2 years were excluded, and all patients with events occurring after 2 years were considered as censored. A logistic regression model was employed, including all the previously selected and validated independent predictors of outcomes. The two-year risk score (predicted probability of event) was computed for each subject by using the estimated logistic coefficients. The score was validated by dividing the sample in deciles of risk and by comparing the observed events with the predicted events in each decile (Hosmer-Lemeshow test). The capacity of the score to correctly classify cases and controls was quantified by the area under the ROC curve. Again, to avoid overestimates, the sample was randomly split in two, the coefficients were estimated in the first half, and the score was tested in the second half. Analogously, we computed ROC curves for risk scores predicting events occurring within 1, 3, and 4 years. All analyses were performed using SAS statistical package v.9.2 (SAS Institute Inc., Cary, NC).

\section{Results}

Patients' demographic, laboratory, echocardiographic and CPET data are reported in Table 1, as well as the number of observations available for each variable. HF treatment, at study run-in, included: beta-blockers in $81 \%$ of patients, ACE-inhibitors in 79\%, ARB- Blockers in $14 \%$, Diuretics in $80 \%$, antialdosteonic drugs in $49 \%$, anticoagulants in $34 \%$, digitalis in $33 \%$, amiodarone in $26 \%$, antiplatelet drugs in $44 \%$. Albeit the presence of a scheduled major cardiovascular treatment was a study exclusion criterion, during the follow up 90 patients underwent cardiac surgery, 53 hemodynamic procedure and 500 CRT/ICD implantation. Female gender was $16 \%$ of cases $(430 / 2286)$. Females had a higher LVEF $32.9 \pm 9.0 \%$ vs. $30.4 \pm 9.1 \%(\mathrm{p}<0.0001)$. Peak $\mathrm{VO}_{2}$ was higher in females compared to males if expressed as a \% of predicted value $(59.0 \pm 16.7 \%$ of pred. vs. $51.7 \pm 15.3, \mathrm{p}<0.0001)$ and lower if expressed as $\mathrm{mL} / \mathrm{min} / \mathrm{kg}(12.9 \pm 4.0 \mathrm{~mL} / \mathrm{min} / \mathrm{kg}$ vs. $14.7 \pm 4.4, \mathrm{p}<0.0001)$.

\subsection{Prognosis}

The median follow up was 1041 days (range 4-5185 days, 75-25 percentile: 1811-513), being the shorter follow up for an alive patient 32 days. Cardiovascular death + urgent cardiac transplant occurred in 529 cases $(19 \%, 441$ cardiac death and 88 urgent cardiac transplant): 139, 110, 79, 51 events in the first, second, third and fourth year, respectively. In Table 1 , univariate analysis of the analyzed
Table 1

Patient demographic, laboratory, echocardiographic, CPET data and univariate analysis of the analyzed parameters vs. the study end point (cardiovascular death + heart transplant).

\begin{tabular}{|c|c|c|c|c|c|c|c|}
\hline & \multicolumn{2}{|c|}{$\begin{array}{l}\text { Mean } \pm \text { SD } \\
\text { median ( } 75-25 \\
\text { interquartile) }\end{array}$} & N (\%) & HR & $\begin{array}{l}\text { Lower } \\
\mathrm{CI}\end{array}$ & $\begin{array}{l}\text { Upper } \\
\text { CI }\end{array}$ & ProbChiSq \\
\hline Age (years) & 60.3 & \pm 12.4 & 2716 & 1.267 & 1.142 & 1.405 & $<.0001$ \\
\hline $\begin{array}{l}\text { Males/ } \\
\text { females }\end{array}$ & & & $\begin{array}{l}2286 \\
(84 \%) / \\
430 \\
(16 \%)\end{array}$ & 1.108 & 1.006 & 1.219 & 0.0367 \\
\hline Height (cm) & 170 & \pm 8 & 2708 & 1 & 0.915 & 1.093 & 1 \\
\hline BMI $\left(\mathrm{kg} / \mathrm{m}^{2}\right)$ & 26.5 & \pm 4.3 & 2707 & 0.815 & 0.742 & 0.895 & $<.0001$ \\
\hline NYHA class & 2.2 & \pm 0.6 & 2716 & 2.257 & 1.951 & 2.61 & $<.0001$ \\
\hline HF ethiology & & & & & & & 0.07 \\
\hline Idiopathic & & & 1273 & 1 & & & \\
\hline Ischemic & & & 1240 & 1.234 & 1.017 & 1.496 & 0.03 \\
\hline Valvular & & & 72 & 0.911 & 0.510 & 1.625 & 0.75 \\
\hline Other & & & 130 & 1.160 & 0.760 & 1.771 & 0.49 \\
\hline PM & & & $\begin{array}{l}498 \\
(18 \%)\end{array}$ & 1.954 & 1.558 & 2.45 & $<.0001$ \\
\hline ICD & & & $\begin{array}{l}461 \\
(17 \%)\end{array}$ & 1.504 & 1.184 & 1.909 & 0.0008 \\
\hline CRT & & & $\begin{array}{l}208 \\
(8 \%)\end{array}$ & 2.329 & 1.692 & 3.206 & $<.0001$ \\
\hline $\mathrm{Hb}(\mathrm{g} / \mathrm{dL})$ & 13.5 & \pm 1.6 & 2271 & 0.722 & 0.652 & 0.8 & $<.0001$ \\
\hline $\mathrm{Na}_{\mathrm{L}}^{+}(\mathrm{mmol} /$ & 139 & \pm 3 & 2524 & 0.775 & 0.712 & 0.844 & $<.0001$ \\
\hline $\begin{array}{l}\mathrm{K}^{+} \\
\quad(\mathrm{mmol} / \mathrm{L})\end{array}$ & 4.3 & \pm 0.5 & 2517 & 0.93 & 0.846 & 1.023 & 0.1368 \\
\hline $\begin{array}{l}\text { Crea } \\
\qquad(\mathrm{mg} / \mathrm{dL})\end{array}$ & 1.21 & \pm 0.40 & 2532 & 1.343 & 1.248 & 1.446 & $<.0001$ \\
\hline $\begin{array}{l}\text { MDRD }(\mathrm{mL} / \\
\min )\end{array}$ & 69.5 & \pm 22.0 & 2531 & 0.698 & 0.631 & 0.772 & $<.0001$ \\
\hline LVEF (\%) & 30.8 & \pm 9.1 & 2716 & 0.539 & 0.486 & 0.597 & $<.0001$ \\
\hline LVeSV (mL) & 111 & $(153-80)$ & 2203 & 1.423 & 1.303 & 1.554 & $<.0001$ \\
\hline LVeDV (mL) & 163 & $(211-121)$ & 2203 & 1.435 & 1.326 & 1.552 & $<.0001$ \\
\hline $\begin{array}{l}\text { Ramp } \\
\text { protocol } \\
\text { (Watt/ } \\
\text { min) })^{\mathrm{a}}\end{array}$ & 10.4 & \pm 2.3 & 2250 & & & & \\
\hline $\begin{array}{l}\text { Peak VO }{ }_{2}(\mathrm{~L} / \\
\text { min) }\end{array}$ & 1.102 & \pm 0.396 & 2699 & 0.538 & 0.483 & 0.599 & $<.0001$ \\
\hline $\begin{array}{l}\text { Peak } \mathrm{VO}_{2} / \mathrm{kg} \\
(\mathrm{mL} / \mathrm{kg} / \\
\mathrm{min})\end{array}$ & 14.4 & \pm 4.4 & 2696 & 0.535 & 0.481 & 0.596 & $<.0001$ \\
\hline $\begin{array}{c}\text { Peak } \mathrm{VO}_{2}(\% \\
\text { of pred) }\end{array}$ & 52.9 & \pm 15.8 & 2695 & 0.52 & 0.47 & 0.576 & $<.0001$ \\
\hline $\begin{array}{r}\text { Peak HR } \\
(\mathrm{bpm})\end{array}$ & 124 & \pm 25 & 2689 & 0.792 & 0.72 & 0.87 & $<.0001$ \\
\hline $\begin{array}{l}\text { Peak HR (\% } \\
\text { of pred) }\end{array}$ & 79 & \pm 16 & 2689 & 0.845 & 0.768 & 0.93 & 0.0006 \\
\hline $\begin{array}{l}\text { Peak work } \\
\text { rate } \\
\text { (Watt) }\end{array}$ & 81.1 & \pm 33.3 & 2408 & 0.527 & 0.459 & 0.605 & $<.0001$ \\
\hline $\begin{array}{l}\text { Peak } \\
\qquad \mathrm{O}_{2} \text { pulse } \\
\text { (mL/bpm) }\end{array}$ & 9.0 & \pm 3.1 & 2672 & 0.616 & 0.555 & 0.684 & $<.0001$ \\
\hline Peak TV (L) & 1.5 & \pm 0.5 & 2516 & 0.759 & 0.688 & 0.839 & $<.0001$ \\
\hline $\begin{array}{l}\text { Peak RR } \\
\text { (bpm) }\end{array}$ & 32.0 & \pm 6.9 & 2441 & 1.16 & 1.056 & 1.275 & 0.002 \\
\hline $\begin{array}{l}\text { Peak VE (L/ } \\
\text { min) }\end{array}$ & 45.4 & \pm 13.6 & 2640 & 0.845 & 0.769 & 0.93 & 0.0005 \\
\hline Peak RER & 1.12 & \pm 0.12 & 2552 & 1.026 & 0.927 & 1.137 & 0.6154 \\
\hline $\begin{array}{l}\mathrm{VO}_{2} \text { at } \mathrm{AT} \\
(\mathrm{mL} / \mathrm{kg} / \\
\mathrm{min})\end{array}$ & 10.1 & \pm 3.2 & 2274 & 0.581 & 0.47 & 0.718 & $<.0001$ \\
\hline $\begin{array}{c}\mathrm{VO}_{2} \text { at } \mathrm{AT}(\% \\
\text { of peak) }\end{array}$ & 69 & \pm 14 & 2274 & 1.162 & 1.043 & 1.296 & 0.0066 \\
\hline $\begin{array}{l}\text { HR at AT } \\
(\mathrm{bpm})\end{array}$ & 99.2 & \pm 20 & 2198 & 0.864 & 0.774 & 0.964 & 0.0092 \\
\hline $\begin{array}{c}\text { Work rate at } \\
\text { AT (Watt) }\end{array}$ & 50.8 & \pm 23.8 & 2139 & 0.69 & 0.603 & 0.79 & $<.0001$ \\
\hline $\begin{array}{l}\mathrm{O}_{2} \text { pulse at } \\
\text { AT } \\
(\mathrm{mL} / \mathrm{bpm})\end{array}$ & 8.0 & \pm 2.7 & 2199 & 0.67 & 0.595 & 0.754 & $<.0001$ \\
\hline
\end{tabular}


Table 1 (continued)

\begin{tabular}{|c|c|c|c|c|c|c|}
\hline & $\begin{array}{l}\text { Mean } \pm \text { SD } \\
\text { median ( } 75-25 \\
\text { interquartile) }\end{array}$ & N (\%) & HR & $\begin{array}{l}\text { Lower } \\
\text { CI }\end{array}$ & $\begin{array}{l}\text { Upper } \\
\text { CI }\end{array}$ & ProbChiSq \\
\hline $\begin{array}{l}\mathrm{VE} / \mathrm{VCO}_{2} \\
\text { slope }\end{array}$ & \pm 7.7 & 2526 & 1.571 & 1.465 & 1.685 & $<.0001$ \\
\hline $\begin{array}{l}\mathrm{VO}_{2} / \text { work } \\
\text { slope } \\
\text { (mL/min/ } \\
\text { Watt) }\end{array}$ & \pm 2.0 & 1689 & 0.868 & 0.745 & 1.01 & 0.067 \\
\hline $\begin{array}{l}\text { Atrial } \\
\text { fibrillation }\end{array}$ & & $\begin{array}{l}448 \\
(17 \%)\end{array}$ & 1.395 & 1.118 & 1.741 & 0.0033 \\
\hline $\begin{array}{l}\text { Periodic } \\
\text { breathing }\end{array}$ & & $\begin{array}{l}540 \\
(20 \%)\end{array}$ & 1.19 & 1.00 & 1.179 & 0.03 \\
\hline
\end{tabular}

$\mathrm{BMI}=$ body mass index, NYHA = New York Heart Association, $\mathrm{HF}=$ heart failure, $\mathrm{PM}=$ pace maker, ICD $=$ implantable cardioverter-defibrillator, $\mathrm{CRT}=$ cardiac resynchronization therapy; $\mathrm{Hb}=$ hemoglobin, $\mathrm{Na}^{+}=$sodium, $\mathrm{K}^{+}=$potassium, Crea $=$creatinine, $\mathrm{MDRD}=$ modification of diet in renal disease, $\mathrm{BNP}=$ brain natriuretic peptide, $\mathrm{LVEF}=$ left ventricular ejection fraction, LVeSV = left ventricular end-systolic volume, LVeDV = left ventricular end-diastolic volume, $\mathrm{VO}_{2}=$ oxygen uptake, $\mathrm{HR}=$ heart rate, $\mathrm{TV}=$ tidal volume, $\mathrm{RR}=$ respiratory rate, $\mathrm{VE}=$ ventilation, $\mathrm{RER}=$ respiratory exchange ratio, $\mathrm{AT}=$ anaerobic threshold, $\mathrm{VCO}_{2}=$ carbon dioxide consumption. Italics: medians and interquartile range.

a Bike ergometer.

parameters vs. the study end-point is reported. At multivariable Cox analysis with subsequent cross validation, only hemoglobin, $\mathrm{Na}^{+}$, MDRD, LVEF, peak $\mathrm{VO}_{2}$ (\% predicted), and $\mathrm{VE} / \mathrm{VCO}_{2}$ slope resulted independently related to prognosis (Table 2). On the basis of these 6 continuous variables, a score of Metabolic Exercise and Cardiac and Kidney Indexes, the MECKI score, was defined to identify the risk of cardiovascular death + urgent heart transplant. A high concordance was detected between two-year predicted and observed risk of death in the entire population, stratified by decile of risk (Fig. 1). Mean \pm SD of each variable included in the MECKI score for the 2 -years mortality risk categories $(<5 \%, 5-10 \%, 10-15 \%,>15 \%)$ is reported in Table 3.

Fig. 2 reports the Kaplan-Meier survival curves stratified according to risk class at 2 years, built on a subset of 2009 subjects who had all the variables included in the MECKI score: $<5 \%$ (906 cases), $5-10 \%$ (449 cases), 10-15\% (236 cases), and >15\% (418 cases). The ROC analysis of the MECKI score is reported in Fig. 3. The MECKI score AUC was $0.804(0.754-0.852)$ at 1 year (1758 survivors and 83 events), $0.789(0.750-0.828)$ at 2 years (1254 survivors and 152 events), $0.762(0.726-0.799)$ at 3 years (1114 survivors and 205 events), and $0.760(0.724-0.796)$ at 4 years (891 survivors and 246 events)

A significant worst prognosis was observed in patients with HF associated to coronary artery disease (Table 1 ), but etiology failed to maintain an independent value at multivariate analysis. Finally, the presence of the some drug categories was related to prognosis at univariate analysis (Table 4), but at multivariable Cox analysis, only beta-blockers ( $\mathrm{HR}=0.692,95 \% \mathrm{HR}$ confidence $0.542-0.883, \mathrm{p}=$ $0.0031)$ and digitalis $(H R=1.433,95 \%$ HR confidence $1.113-1.845$, $\mathrm{p}=0.0053$ ) remained independently related to prognosis. However, both beta-blockers and digitalis failed at cross-validation procedure. If beta-blockers and digitalis were forced in the MECKI score, the AUC curve at 2 years changed from 0.789 to 0.791 .

A free web-based calculator was developed to allow an easy and convenient calculation of the estimated risk of death. http://www. cardiologicomonzino.it/Inglese/News/Pages/UserNewsHome.aspx

\section{Discussion}

Many HF risk stratification tools were developed, each differing in the type of sample from which it was derived and validated, the variable used for risk stratification, their utility in predicting mortality at varying time points, and their ease of use. However, their application in daily clinical practice is limited by their complexity [23], albeit a
Table 2

Variables which remained significantly related to the primary study endpoint (cardiovascular death + cardiac transplant) at multivariable Cox analysis with subsequent cross validation.

\begin{tabular}{|c|c|c|c|c|c|c|}
\hline Parameter & $\operatorname{Pr}>$ ChiSq & Hazard ratio & \multicolumn{2}{|c|}{$\begin{array}{l}\text { 95\% hazard } \\
\text { ratio } \\
\text { confidence } \\
\text { limits }\end{array}$} & Selection & Reconfirmation \\
\hline $\begin{array}{l}\text { Peak } \mathrm{VO}_{2} \\
\text { (\% pred) }\end{array}$ & $<.0001$ & 0.708 & 0.614 & 0.816 & $84.0 \%$ & $93.5 \%$ \\
\hline $\begin{array}{l}\mathrm{VE} / \mathrm{VCO}_{2} \\
\text { slope }\end{array}$ & $<.0001$ & 1.291 & 1.165 & 1.431 & $85.0 \%$ & $95.3 \%$ \\
\hline $\mathrm{Hb}(\mathrm{g} / \mathrm{dL})$ & 0.0008 & 0.827 & 0.74 & 0.924 & $85.5 \%$ & $94.2 \%$ \\
\hline $\begin{array}{l}\mathrm{Na}^{+} \\
\quad(\mathrm{mmol} / \mathrm{L})\end{array}$ & $<.0001$ & 0.796 & 0.719 & 0.881 & $96.5 \%$ & $92.7 \%$ \\
\hline LVEF (\%) & $<.0001$ & 0.699 & 0.61 & 0.802 & $90.0 \%$ & $93.9 \%$ \\
\hline $\begin{array}{l}\text { MDRD } \\
\qquad(\mathrm{mL} / \mathrm{min})\end{array}$ & $<.0001$ & 0.758 & 0.673 & 0.854 & $66.0 \%$ & $81.1 \%$ \\
\hline
\end{tabular}

See Table 1 for abbreviations.

few easier to use approaches have been proposed [24] or because they are considered as suboptimal in particular settings [23]. We developed a new predictive model built and validated on contemporary HF population, based on simple parameters selected form several measurements of clinical status, cardiac kidney function, anemia, fluid homeostasis and exercise performance. We aimed, to help clinicians in the risk stratification of ambulatory HF patients.

Ultimately, several CPET and prognosis studies in systolic HF have provided, improved, and updated risk stratification. Since prediction models should be designed to improve outcome definition in individual patients, the integration of CPET risk factors with demographic data, medical history, laboratory values, and HF treatment background is crucial. Unfortunately, the combination between intraand extra-CPET risk HF data has been poorly investigated. The MECKI score fills the gap, and its clinical insight and originality lies in the ability to amalgamate a modern CPET risk interpretation with easily accessible HF predictive data. Thus, the clinical difficulty of merging intraand extra-ergospirometry laboratory risk parameters is surmounted

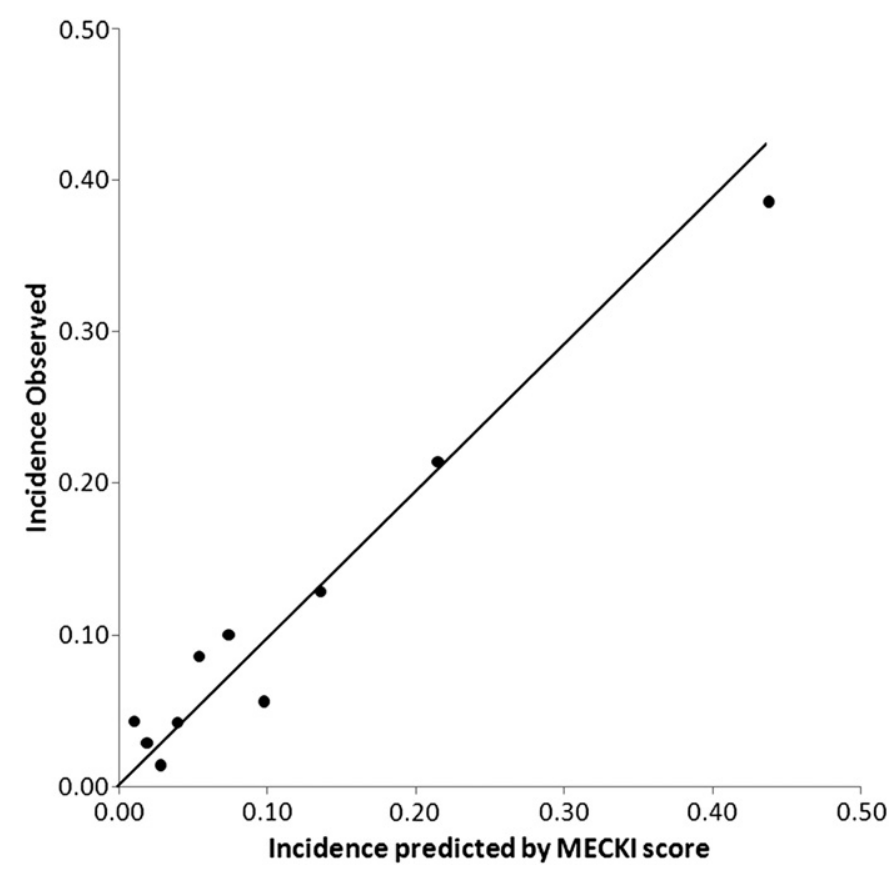

Fig. 1. Comparison between two-year predicted and observed risk of death in the entire population, stratified by decile of risk. Relevant concordance was observed: $p=$ 0.36 at Hosmer-Lemeshow Test. The straight line is an identity line. 
Table 3

Mean \pm SD of the variables included in the MECKI score divided according to risk class at 2 years, $<5 \%, 5-10 \%, 10-15 \%$, and $>15 \%$.

\begin{tabular}{|c|c|c|c|c|c|c|}
\hline & $\begin{array}{l}\text { LVEF } \\
(\%)\end{array}$ & $\begin{array}{l}\text { Peak } \mathrm{VO}_{2} \\
(\%)\end{array}$ & $\begin{array}{l}\mathrm{Na}^{+} \\
(\mathrm{mmol} / \mathrm{L})\end{array}$ & $\begin{array}{l}\mathrm{Hb} \\
(\mathrm{g} / \mathrm{dL})\end{array}$ & $\begin{array}{l}\text { MDRD } \\
(\mathrm{mL} / \mathrm{min})\end{array}$ & $\mathrm{VE} / \mathrm{VCO}_{2}$ slope \\
\hline$<5 \%$ & $36.74 \pm 7.35$ & $61.92 \pm 14.16$ & $140.4 \pm 3.1$ & $13.9 \pm 1.5$ & $77.09 \pm 20.91$ & $28.67 \pm 4.6$ \\
\hline $5-10$ & $29.28 \pm 7$ & $51.55 \pm 11.29$ & $139.7 \pm 3.2$ & $13.4 \pm 1.6$ & $68.89 \pm 20.26$ & $32.62 \pm 5.13$ \\
\hline $10-15$ & $26.88 \pm 7.08$ & $45.6 \pm 10.25$ & $138.8 \pm 3.2$ & $13.3 \pm 1.5$ & $62.94 \pm 20.77$ & $34.86 \pm 5.45$ \\
\hline$>15 \%$ & $23.75 \pm 6.77$ & $38.2 \pm 9.94$ & $137.7 \pm 3.7$ & $13.0 \pm 1.64$ & $56.43 \pm 20.21$ & $41.98 \pm 7.96$ \\
\hline
\end{tabular}

See Table 1 for abbreviations.

by the MECKI score, since it allows an appropriate risk definition before the HF patient leaves the ergospirometry laboratory.

\subsection{The MECKI score}

The MECKI score is the result of a merging effort of 13 qualified HF centers with significant experience in CPET. Our study population consists of systolic HF patients capable to perform a CPET, excluding, therefore, subjects in NYHA class IV at enrollment as well as subjects who failed to complete a maximal CPET. Out of the 6 indexes independently related to prognosis at multivariable analysis, 2 are CPETderived parameters, either related to the cardiovascular (peak $\mathrm{VO}_{2}$ ) or to the ventilatory $\left(\mathrm{VE} / \mathrm{VCO}_{2}\right.$ slope) response to effort. Beside these parameters, the MECKI score uses an echocardiographic index of cardiac systolic function (LVEF), 2 indexes of harmful comorbidities (anemia and renal insufficiency: hemoglobin concentration and MDRD, respectively), and one index of fluid balance (serum $\mathrm{Na}^{+}$). All the variables included within the MECKI score were continuous values, so that the actual weight of each one was considered. The
6 parameters had a significant impact on the score calculation (Table 2), their distribution significantly overlapped (Table 3), confirming the need to pool the available information for an accurate prognosis. Notably, all prognostic parameters were evaluated by using a cross-validation procedure, splitting the population in two halves and considering as significant only parameters which were selected and confirmed in at least $70 \%$ of the 200 times they were tested.

We analyzed 3 different units of $\mathrm{VO}_{2}$ at peak exercise, and specifically peak $\mathrm{VO}_{2}$ as $\mathrm{L} / \mathrm{min}$, as $\mathrm{mL} / \mathrm{min} / \mathrm{kg}$, and as \% of predicted. The last one was the only peak $\mathrm{VO}_{2}$ measurement included in the MECKI score. Conversely, peak $\mathrm{VO}_{2} \%$ pred. has been preferred to peak $\mathrm{VO}_{2}$ absolute measurements in only a few reports [25-27]. The presence of gender and age in peak $\mathrm{VO}_{2} \%$ pred. [20], as well as in the MDRD calculation [18], is among the possible reasons why both disappear from the final score. In any case, if gender and age are forced in the MECKI score, their additive value is negligible.

We calculated the $\mathrm{VE} / \mathrm{VCO}_{2}$ slope up to the end of the isocapnic buffering period. The average $\mathrm{VE} / \mathrm{VCO}_{2}$ value observed in our population

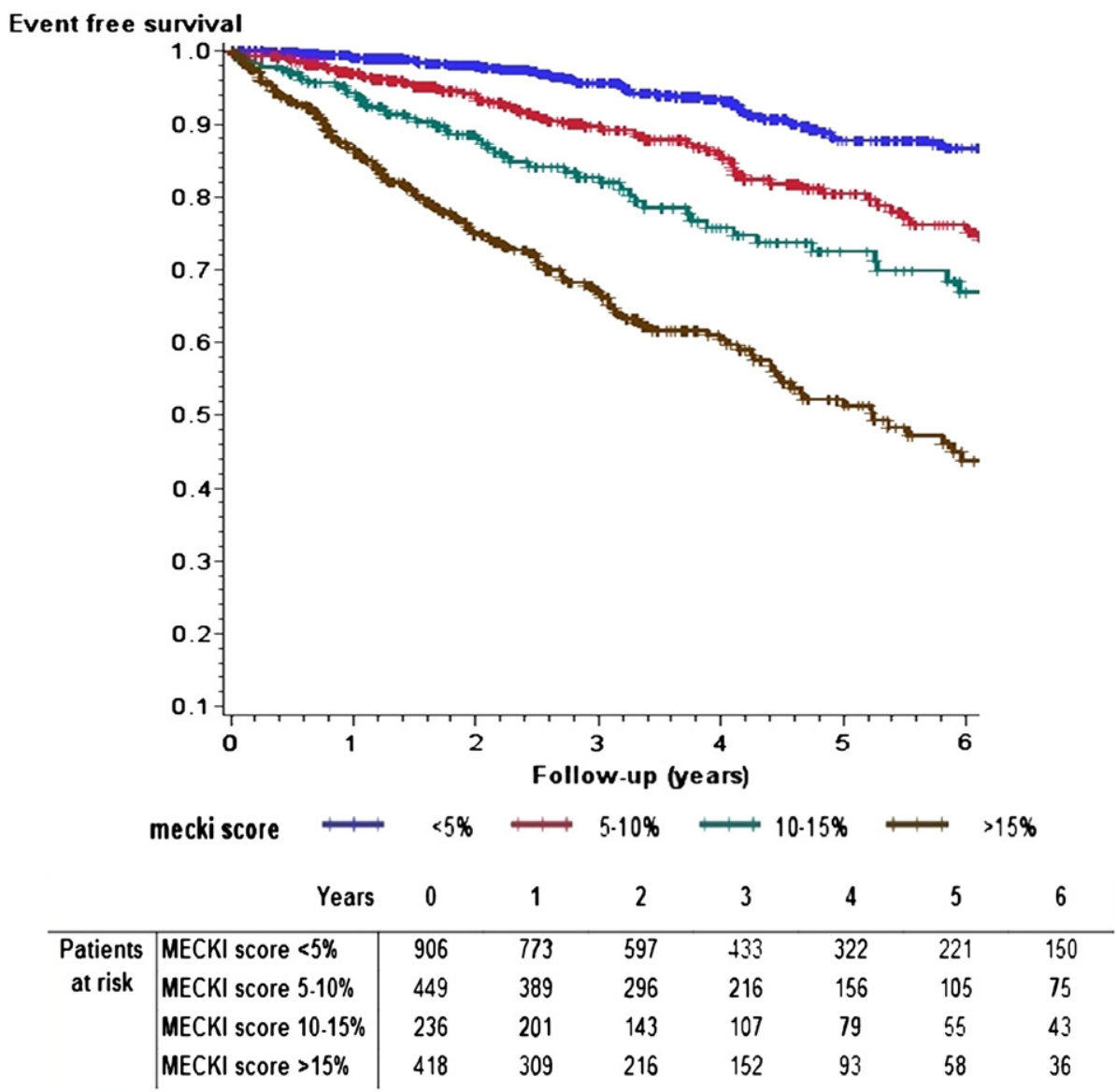

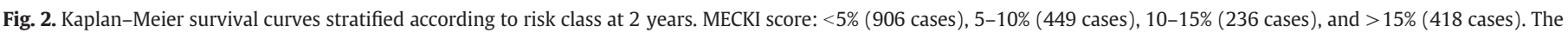
curves were arbitrarily ended at 6 years. 


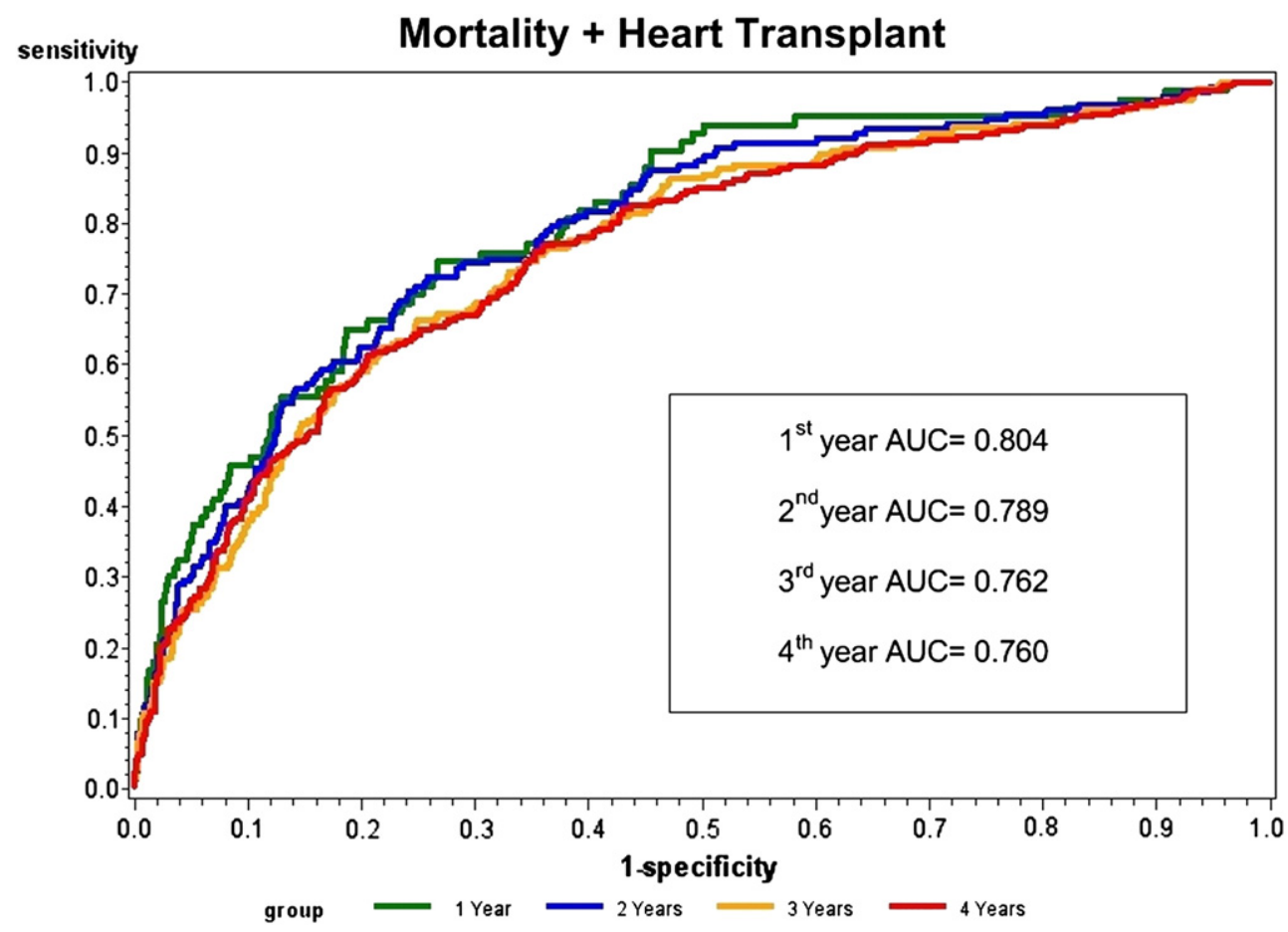

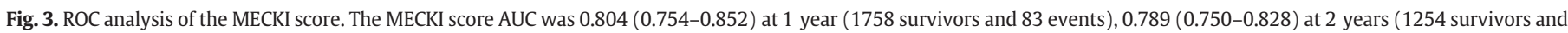
152 events) $0.762(0.726-0.799)$ at 3 years (1114 survivors and 205 events) and 0.760 (0.724-0.796) at 4 years (891 survivors and 246 events).

was 33 , which is the value usually considered as the threshold between poor and favorable prognosis in HF $[3,4,28]$. Our observations agree with several previous studies that have reported the combined role of peak $\mathrm{VO}_{2}$ and $\mathrm{VE} / \mathrm{VCO}_{2}$ in predicting $\mathrm{HF}$ prognosis [6,7].

In the present population, periodic breathing was significantly related to prognosis as previously reported $[5,22,29]$ at univariate but not at multivariable analysis. However, albeit we used a simple definition of periodic breathing, its assessment may be difficult in some cases. Moreover, it is possible, because of the multifactorial genesis of periodic breathing, that the presence of other non CPET-derived parameters in the MECKI score, such as LVEF, hemoglobin, $\mathrm{Na}^{+}$and MDRD, not previously evaluated, overcomes the role of periodic breathing.

It is not surprising that LVEF remains significantly related to prognosis $[10,23,30]$. Indeed, several reports, some of which date back to many years ago, suggested that LVEF, representing the extent of the cardiac damage, has a prognostic value in $\mathrm{HF}$, regardless of peak $\mathrm{VO}_{2}[30]$.

Table 4

Univariate analysis of the drug used at study run-in vs. the study end point (cardiovascular death + heart transplant).

\begin{tabular}{lllll}
\hline Parameter & HR & Lower CI & Upper CI & ProbChiSq \\
\hline ACE-inhibitors & 0.897 & 0.698 & 1.152 & 0.393 \\
ARB-blockers & 0.889 & 0.662 & 1.195 & 0.4363 \\
Beta-blockers & 0.572 & 0.466 & 0.701 & $<.0001$ \\
Diuretics & 1.842 & 1.383 & 2.453 & $<.0001$ \\
Anti-aldosteronic drugs & 1.207 & 1.01 & 1.444 & 0.039 \\
Anti-platlets drugs & 0.882 & 0.735 & 1.059 & 0.1789 \\
Anticoagulants & 1.423 & 1.189 & 1.702 & 0.0001 \\
Digitalis & 1.964 & 1.619 & 2.384 & $<.0001$ \\
Amiodarone & 1.622 & 1.342 & 1.96 & $<.0001$ \\
\hline
\end{tabular}

$\mathrm{ACE}=$ angiotensin $\mathrm{I}$ converting enzyme, $\mathrm{ARB}=$ angiotensin II receptor.
Low hemoglobin was associated with an increased risk of death in our population, confirming the report of anemia as a risk factor in $\mathrm{HF}$ $[15,16]$. Hemoglobin effect on HF prognosis was not cancelled by $\mathrm{VO}_{2}$, even if hemoglobin is a major determinant of peak $\mathrm{VO}_{2}$ [31].

$\mathrm{Na}^{+}$and renal function are both well-known prognostic elements for HF [18,32-34]. We showed that they maintain a prognostic role even in the combined analysis of several variables. As expected, MDRD was superior to serum creatinine level, since it also considers gender and age [18].

The role of gender in HF prognosis is important, but definite data are lacking $[35,36]$. In the present work, gender did not reach, at multivariable analysis, statistical significance, but it is considered in other parameters included in the MECKI score, such as peak $\mathrm{VO}_{2} \%$ pred. and MDRD. We showed a better HF prognosis in women compared to men. In the few previous reports available, women, albeit a lower peak $\mathrm{VO}_{2}$, showed a better HF prognosis compared to men $[37,38]$. Interestingly, peak $\mathrm{VO}_{2}$ was previously reported as an absolute value $[37,38]$. In the present report, peak $\mathrm{VO}_{2}$ as an absolute value is lower in women compared to men, and higher if reported as \% of predicted.

Differently from previous reports $[10,23,35,39]$, HF etiology was not related to prognosis, albeit the presence of coronary artery disease was associated to a worse prognosis at univariable analysis. At multivariable analysis, the presence of digitalis and beta-blockers at study run-in was negatively and positively associated to prognosis, respectively, while this is not the case for other drugs, such as ACE-inhibitors, diuretics, ARB-blockers [10,23,40]. We believe that this is related to the optimal treatment of the study population, and the presence of digitalis and the absence of beta-blockers merely reflect a more severe HF. Indeed, only a minority of patients, $19 \%$, were not on beta-blocker treatment at study run-in. These patients had severe heart failure as demonstrated by peak $\mathrm{VO}_{2}=13.9 \pm 4.2$ and $\mathrm{VE} / \mathrm{VCO}_{2}$ slope $=34.7 \pm 8.9$. Similarly, patients treated with digitalis, $33 \%$ of cases, had a higher incidence of atrial fibrillation (25\%) and a peak $\mathrm{VO}_{2}=14.1 \pm 4.2$ and $\mathrm{VE} / \mathrm{VCO}_{2}$ slope $33.4 \pm 7.8$. Moreover, 
it is recognized that we have not performed a drug dose analysis which might have influenced the MECKI score [40]. Indeed, it is possible that several patients of the present study were not in drug target dose [41]. However, because the presence of beta-blockers and digitalis failed at cross-validation procedure, and because drug treatment is a skewed decision and not an independent variable, we decided not to add digitalis and beta-blockers into the MECKI score. We were also supported in this approach by the finding that adding both beta-blockers and digitalis to the MECKI score has a negligible effect on the AUC.

\subsection{Comparison with other HF scores and clinical implications}

Several HF scores have been suggested and investigated [10,11,23], but their predictive accuracy is variable, depending on the illness course, the background HF therapy, i.e. beta-blockers prescription [23], device implantation [11,23], the type of events (i.e. inclusion of HF hospitalization) and the duration of follow up. Hence, a comprehensive comparative analysis between HF scores is difficult and, sometimes, not exhaustive [43].

HFSS was the first multivariate HF model, and it was validated in different settings [10,12-14,38,44,45]. Variables included are ischemic etiology, LVEF, mean blood pressure, heart rate, a QRS width of 120 milliseconds or more, serum sodium, and peak $\mathrm{VO}_{2}$. The model divides patients into risk groups: low, moderate, and high. The SHFM is the most validated model for HF prognostication [23], both in clinical trials [46-48] and in community-based heart failure studies [49]: even though effective and efficient, the SHFM is complex, being a 20-variable model, including age, sex, weight, LVEF, systolic blood pressure, NYHA class, daily diuretic dose, sodium, hemoglobin, percent lymphocytes, uric acid, and total cholesterol. In addition, ACE enzyme inhibitors, angiotensin receptor blockers, aldosterone blockers, beta-blockers, statins, and devices are taken into account. Data aggregation is demanding, but score definition is alleviated by online and downloadable versions of calculators. The SHFM may be useful if peak $\mathrm{VO}_{2}$ cannot be obtained, due to the inability to exercise, or if peak $\mathrm{VO}_{2}$ is unreliable, due to low respiratory exchange ratio.

The HF-ACTION predictive risk score model is a new HF score [11]: 48 candidate variables were analyzed, including demographic data, medical history, laboratory values, exercise parameters from maximal treadmill CPET, and measures of quality of life and depression. Exercise duration on CPET, Kansas City Cardiomyopathy Questionnaire symptom stability score, higher serum urea nitrogen, and male sex formed the best predictive model for the primary end-point (all-cause mortality or hospitalization).

Each HF score has constructive and drawback features: the SHFM is a complex 20-variable model and it uses NYHA class as a surrogate for peak $\mathrm{VO}_{2}$, the HFSS is a 7-variable model that requires peak $\mathrm{VO}_{2}$, often available only in specialized referral centers, and the HF-action score promotes a 4-variables mode, in HF patients performing a maximal CPET, without including peak $\mathrm{VO}_{2}$.

Do we need another HF score? The MECKI score is a "CPET-centered" score, and it emphasizes a modern interpretation of CPET results. For the first time, $\mathrm{VE} / \mathrm{VCO}_{2}$ and $\%$ of predicted $\mathrm{VO}_{2}$ (rather than peak $\mathrm{VO}_{2}$ ) were included in the model. It is worthy of note that these two CPET variables were selected from 18 ergospirometric parameters, providing a desirable hierarchy, limiting the expanding number of CPET risk parameters applied to predict outcome. In the MECKI score, CPET scoring system was kept as simple as possible. In short, on one hand the MECKI score underlines the central role of CPET for risk stratification, and on the other hand it underscores that both ventilatoryand $\mathrm{VO}_{2}$-derived indexes should be considered. In addition, although the MECKI score is "CPET-centered", providing a modern and sophisticated gas-exchange analysis, it underlines the opportunity to look "outside" the ergospirometry laboratory, and it corroborates that CPET risk utilization should be conducted in aggregation with non CPET outcome data $[10,11]$.

\subsection{Study limitations}

This study has a few limitations, which should be considered when applying the MECKI score in the clinical setting. Firstly, we studied a Caucasian population with $~ 50 \%$ of patients suffering from idiopathic cardiomyopathy. Our population mainly consists in relatively young HF males capable to perform an exercise and with a low comorbidity rate. Therefore, the present population does not mirror the real medical world. Consequently the MECKI score is only applicable to HF subjects who have performed a maximal CPET. Moreover, we do not know if the MECKI score maintains its prognostic power in other HF populations, such as subjects not on optimized treatment, or in not Caucasian or elderly subjects. Regarding the HF population studied, it is acknowledged that, albeit we selected our HF population to avoid significant comorbidities which could directly affect exercise capacity and prognosis, we did not exclude from the present study patients with systemic hypertension, diabetes, and moderate COPD. Accordingly, we cannot rule out a specific role of these comorbidities on exercise capacity, on prognosis, and consequently on the MECKI score. The above-mentioned characteristics of our study population and particularly the capability of performing a CPET, make the comparison between our data and those of HF registry or epidemiological studies [23,32,50-53] difficult. Altogether the above reported limitations explain why we obtained a relative small number of patients per center. Secondly, we did not consider, on top of the NYHA classification, findings such as history of HF hospitalization, presence of mitral regurgitation, 3rd tone, right heart dysfunction, jugular distension, hepatomegaly, or peripheral edema, all surrogates of clinical severity. Thirdly, we observed a $R E R<1.0$ in $330(12 \%)$ patients, which suggests a submaximal exercise test. However, CPET was self-interrupted by the patients when they had reached maximal effort. Notably, in 74 out of 330 patients, exercise-induced periodic breathing was observed, questioning the value of RER as a parameter of peak exercise achievement. Moreover, it should be noted that the value of RER was not related to prognosis even at univariate analysis. Fourthly, we only analyzed ECGs for the presence of atrial fibrillation or for exercise-induced ECG changes. Therefore, the presence of intraventricular delay was not taken into account, albeit left bundle branch block is a recognized HF prognostic parameter. Neither BNP nor NT-pro BNP plasma level, obtained in 793 patients (29\% of cases), were considered in the present analysis, because of jeopardized data, due to the different attitudes of the centers on this regard (routine use in a minority, different peptide assessment, different methods for the same peptide), not allowing pooling and statistical analysis. Fifth, several formulas are available to estimate renal function. We used the MDRD formula [18], but others have been used including the Cockcroft-Gault [54]. We arbitrarily chose MDRD because we are hoping for a widespread use of the MECKI score and racial differences are taken into account in MDRD but not in Cockcroft-Gault formula. Finally it should be acknowledged that, because the follow-up was long, many patients underwent to therapy upgrading, including ICD and CRT which may, per se, have influenced the prognosis.

\subsection{In conclusion}

In this is study parameters obtained from CPET have been combined to other prognostics variables derived from clinical, echocardiographic and laboratory settings in a large cohort of systolic HF patients followed in experienced centers. This allows us to build up a valuable long-term HF prognostic score. Indeed, the MECKI score combines peak $\mathrm{VO}_{2} \%$ of predicted, $\mathrm{VE} / \mathrm{VCO}_{2}$ slope, $\mathrm{LVEF}$, hemoglobin, $\mathrm{Na}^{+}$, and MDRD. Thus the MECKI score is built on only 4 easy to 
obtain clinical variables on top of the two most known prognostic parameters obtained from CPET. Accordingly the MECKI score is a simple, reliable, easy to calculate, personalized heart failure prognostic tool. At present, MECKI is the long term prognostic score for systolic HF with the highest AUC [43]. However, the day-by-day use of the MECKI score as well as the comparisons with existing standards is the next steps needed.

\section{Acknowledgment}

The authors of this manuscript have certified that they comply with the Principles of Ethical Publishing in the International Journal of Cardiology.

\section{Appendix 1}

Other members of the MECKI score research group are: Centro Cardiologico Monzino, IRCCS, Milano: Laura Antonioli, Chiara Segurini, Erica Bertella, Stefania Farina, Francesca Bovis, Cardiologia Riabilitativa, Azienda Ospedali Riuniti, Ancona: Francesca Pietrucci, Istituto Auxologico Italiano: Gabriella Malfatto, Cardiologia SUN, Ospedale Monaldi Napoli, Teo Roselli, Andrea Buono, Raffaele Calabrò, CNR-Milano: Renata De Maria, "S. Maugeri" Foundation, IRCCS, Cassano Murge: Daniela Santoro, Saba Campanale, Domenica Caputo, "S. Maugeri" Foundation, Tradate: Donatella Bertipaglia, Ospedali Riuniti and University of Trieste: Emanuela Berton.

\section{Appendix 2}

Patients' recruitment: 602 patients were recruited and followed at Centro Cardiologico Monzino, Milan, 334 at S. Maugeri Foundation, Cassano Murge, 218 at Fondazione G. Monasterio, Pisa, 127 at S. Maugeri Foundation, Tradate, 57 at Lancisi Hospital, Ancona, 134 at Monaldi Hospital, Naples, 270 at S. Spirito Hospital, Rome, 22 at S. Luca Hospital, Milan, 63 at S. Paolo Hospital, Milan, 266 at Ospedali Civili, Brescia, 201 at Ospedali Riuniti, Trieste, 357 at S. Maugeri Foundation, Veruno and 64 at S. Camillo Hospital, Rome.

\section{References}

[1] O'Neill JO, Young JB, Pothier CE, Lauer MS. Peak oxygen consumption as a predictor of death in patients with heart failure receiving beta-blockers. Circulation 2005;111:2313-8.

[2] Opasich C, Pinna GD, Bobbio M, et al. Peak exercise oxygen consumption in chronic heart failure: toward efficient use in the individual patient. J Am Coll Cardiol 1998;31:766-75.

[3] Kleber FX, Vietzke G, Wernecke KD, et al. Impairment of ventilatory efficiency in heart failure: prognostic impact. Circulation 2000;101:2803-9.

[4] Ponikowski P, Francis DP, Piepoli MF, et al. Enhanced ventilatory response to exercise in patients with chronic heart failure and preserved exercise tolerance: marker of abnormal cardiorespiratory reflex control and predictor of poor prognosis. Circulation 2001;103:967-72.

[5] Arena R, Myers J, Abella J, et al. Development of a ventilatory classification system in patients with heart failure. Circulation 2007;115:2410-7.

[6] Francis DP, Shamim W, Davies LC, et al. Cardiopulmonary exercise testing for prognosis in chronic heart failure: continuous and independent prognostic value from VE/VCO(2)slope and peak VO(2). Eur Heart J 2000;21:154-61.

[7] Corra U, Mezzani A, Bosimini E, Scapellato F, Imparato A, Giannuzzi P. Ventilatory response to exercise improves risk stratification in patients with chronic heart failure and intermediate functional capacity. Am Heart J 2002;143:418-26.

[8] Stevenson LW, Sietsema K, Tillisch JH, et al. Exercise capacity for survivors of cardiac transplantation or sustained medical therapy for stable heart failure. Circulation 1990;81:78-85.

[9] Mancini DM, Eisen H, Kussmaul W, Mull R, Edmunds Jr LH, Wilson JR. Value of peak exercise oxygen consumption for optimal timing of cardiac transplantation in ambulatory patients with heart failure. Circulation 1991;83:778-86.

[10] Aaronson KD, Schwartz JS, Chen TM, Wong KL, Goin JE, Mancini DM. Development and prospective validation of a clinical index to predict survival in ambulatory patients referred for cardiac transplant evaluation. Circulation 1997;95:2660-7.

[11] O'Connor CM, Whellan DJ, Wojdyla D, et al. Factors related to morbidity and mortality in patients with chronic heart failure with systolic dysfunction: the HF-ACTION predictive risk score model. Circ Heart Fail 2011;5:63-71.
[12] Parikh MN, Lund LH, Goda A, Mancini D. Usefulness of peak exercise oxygen consumption and the heart failure survival score to predict survival in patients $>65$ years of age with heart failure. Am J Cardiol 2009;103:998-1002.

[13] Lund LH, Aaronson KD, Mancini DM. Validation of peak exercise oxygen consumption and the heart failure survival score for serial risk stratification in advanced heart failure. Am J Cardiol 2005;95:734-41.

[14] Goda A, Lund LH, Mancini DM. Comparison across races of peak oxygen consumption and heart failure survival score for selection for cardiac transplantation. Am J Cardiol 2010;105:1439-44.

[15] Kazory A, Ross EA. Anemia: the point of convergence or divergence for kidney disease and heart failure? J Am Coll Cardiol 2009;53:639-47.

[16] Anker SD, Comin Colet J, Filippatos G, et al. Ferric carboxymaltose in patients with heart failure and iron deficiency. N Engl J Med 2009;361:2436-48.

[17] Piepoli MF, Corra U, Agostoni PG, et al. Statement on cardiopulmonary exercise testing in chronic heart failure due to left ventricular dysfunction: recommendations for performance and interpretation Part II: How to perform cardiopulmonary exercise testing in chronic heart failure. Eur J Cardiovasc Prev Rehabil 2006;13:300-11.

[18] Hillege HL, Nitsch D, Pfeffer MA, et al. Renal function as a predictor of outcome in a broad spectrum of patients with heart failure. Circulation 2006;113:671-8.

[19] Lang RM, Bierig M, Devereux RB, et al. Recommendations for chamber quantification. Eur J Echocardiogr 2006:7:79-108.

[20] Wasserman K, Hansen JE, Sue DY, Stringer WW, Whipp BJ. Clinical exercise testing. Principles of exercise testing and interpretation including pathophysiology and clinical applications. Lippincott Williams \& Wilkins; 2005. p. 138-9.

[21] Agostoni P, Bianchi M, Moraschi A, et al. Work-rate affects cardiopulmonary exercise test results in heart failure. Eur J Heart Fail 2005;7:498-504.

[22] Corra U, Pistono M, Mezzani A, et al. Sleep and exertional periodic breathing in chronic heart failure: prognostic importance and interdependence. Circulation 2006;113:44-50

[23] Levy WC, Mozaffarian D, Linker DT, et al. The Seattle Heart Failure Model: prediction of survival in heart failure. Circulation 2006;113:1424-33.

[24] Zugck C, Kruger C, Kell R, et al. Risk stratification in middle-aged patients with congestive heart failure: prospective comparison of the Heart Failure Survival Score (HFSS) and a simplified two-variable model. Eur J Heart Fail 2001;3: 577-85.

[25] Osada N, Chaitman BR, Miller LW, et al. Cardiopulmonary exercise testing identifies low risk patients with heart failure and severely impaired exercise capacity considered for heart transplantation. J Am Coll Cardiol 1998;31:577-82.

[26] Stelken AM, Younis LT, Jennison SH, et al. Prognostic value of cardiopulmonary exercise testing using percent achieved of predicted peak oxygen uptake for patients with ischemic and dilated cardiomyopathy. J Am Coll Cardiol 1996;27: 345-52.

[27] Arena R, Myers J, Abella J, et al. Determining the preferred percent-predicted equation for peak oxygen consumption in patients with heart failure. Circ Heart Fail 2009;2:113-20.

[28] Gitt AK, Wasserman K, Kilkowski C, et al. Exercise anaerobic threshold and ventilatory efficiency identify heart failure patients for high risk of early death. Circulation 2002;106:3079-84.

[29] Sun XG, Hansen JE, Beshai JF, Wasserman K. Oscillatory breathing and exercise gas exchange abnormalities prognosticate early mortality and morbidity in heart failure. J Am Coll Cardiol 2010;55:1814-23.

[30] Cohn JN, Archibald DG, Ziesche S, et al. Effect of vasodilator therapy on mortality in chronic congestive heart failure. Results of a Veterans Administration Cooperative Study. N Engl J Med 1986;314:1547-52.

[31] Agostoni P, Salvioni E, Debenedetti C, et al. Relationship of resting hemoglobin concentration to peak oxygen uptake in heart failure patients. Am J Hematol 2010;85:414-7.

[32] Brophy JM, Dagenais GR, McSherry F, Williford W, Yusuf S. A multivariate mode for predicting mortality in patients with heart failure and systolic dysfunction. Am J Med 2004;116:300-4.

[33] Go AS, Chertow GM, Fan D, McCulloch CE, Hsu CY. Chronic kidney disease and the risks of death, cardiovascular events, and hospitalization. N Engl J Med 2004;351: 1296-305.

[34] Gheorghiade M, Abraham WT, Albert NM, et al. Relationship between admission serum sodium concentration and clinical outcomes in patients hospitalized for heart failure: an analysis from the OPTIMIZE-HF registry. Eur Heart J 2007;28: 980-8.

[35] Frazier CG, Alexander KP, Newby LK, et al. Associations of gender and etiology with outcomes in heart failure with systolic dysfunction: a pooled analysis of 5 randomized control trials. J Am Coll Cardiol 2007:49:1450-8.

[36] Gustafsson F, Torp-Pedersen C, Burchardt H, et al. Female sex is associated with a better long-term survival in patients hospitalized with congestive heart failure. Eur Heart J 2004;25:129-35.

[37] Elmariah S, Goldberg LR, Allen MT, Kao A. Effects of gender on peak oxygen consumption and the timing of cardiac transplantation. J Am Coll Cardiol 2006;47: 2237-42.

[38] Green P, Lund LH, Mancini D. Comparison of peak exercise oxygen consumption and the Heart Failure Survival Score for predicting prognosis in women versus men. Am J Cardiol 2007;99:399-403.

[39] Myers J, Gullestad L, Vagelos R, et al. Clinical, hemodynamic, and cardiopulmonary exercise test determinants of survival in patients referred for evaluation of heart failure. Ann Intern Med 1998;129:286-93.

[40] Zugck C, Haunstetter A, Kruger C, et al. Impact of beta-blocker treatment on the prognostic value of currently used risk predictors in congestive heart failure. J Am Coll Cardiol 2002;39:1615-22. 
[41] Domanski M, Norman J, Pitt B, Haigney M, Hanlon S, Peyster E. Diuretic use, progressive heart failure, and death in patients in the studies of left ventricular dysfunction (SOLVD). J Am Coll Cardiol 2003;42:705-8.

[42] Maggioni AP, Dahlstrom U, Filippatos G, et al. EURObservational Research Programme: the Heart Failure Pilot Survey (ESC-HF Pilot). Eur J Heart Fail 2010;12: 1076-84.

[43] Nakayama M, Osaki S, Shimokawa H. Validation of mortality risk stratification models for cardiovascular disease. Am J Cardiol 2011:108:391-6.

[44] Lund LH, Aaronson KD, Mancini DM. Predicting survival in ambulatory patients with severe heart failure on beta-blocker therapy. Am J Cardiol 2003;92: $1350-4$.

[45] Goda A, Lund LH, Mancini D. The heart failure survival score outperforms the peak oxygen consumption for heart transplantation selection in the era of device therapy. J Heart Lung Transplant 2011;30:315-25.

[46] Pitt B, Poole-Wilson PA, Segal R, et al. Effect of losartan compared with captopril on mortality in patients with symptomatic heart failure: randomised trial-the Losartan Heart Failure Survival Study ELITE II. Lancet 2000;355:1582-7.

[47] Mann DL, McMurray JJ, Packer M, et al. Targeted anticytokine therapy in patients with chronic heart failure: results of the Randomized Etanercept Worldwide Evaluation (RENEWAL). Circulation 2004;109:1594-602.
[48] Cohn JN, Tognoni G. A randomized trial of the angiotensin-receptor blocker valsartan in chronic heart failure. N Engl J Med 2001;345:1667-75.

[49] May HT, Horne BD, Levy WC, et al. Validation of the Seattle Heart Failure Model in a community-based heart failure population and enhancement by adding B-type natriuretic peptide. Am J Cardiol 2007;100:697-700.

[50] Butler J, Kalogeropoulos A, Georgiopoulou V, et al. Incident heart failure prediction in the elderly: the health ABC heart failure score. Circ Heart Fail 2008;1: 125-33.

[51] Fonarow GC, Adams Jr KF, Abraham WT, Yancy CW, Boscardin WJ. Risk stratification for in-hospital mortality in acutely decompensated heart failure: classification and regression tree analysis. JAMA 2005;293:572-80.

[52] Gupta S, Rohatgi A, Ayers CR. Risk scores versus natriuretic peptides for identifying prevalent stage B heart failure. Am Heart J 2011;161:923-30 e2.

[53] Giamouzis G, Kalogeropoulos AP, Georgiopoulou VV, et al. Incremental value of renal function in risk prediction with the Seattle Heart Failure Model. Am Heart J 2009;157:299-305.

[54] Zamora E, Lupon J, Vila J, et al. Estimated glomerular filtration rate and prognosis in heart failure: value of the modification of diet in renal disease study-4, chronic kidney disease epidemiology collaboration, and Cockroft-Gault formulas. J Am Coll Cardiol 2012;59:1709-15. 